\title{
Erratum to: Motor, Emotional, and Cognitive Empathy in Children and Adolescents with Autism Spectrum Disorder and Conduct Disorder
}

Danielle Bons • Egon van den Broek • Floor Scheepers • Pierre Herpers • Nanda Rommelse • Jan K. Buitelaar

Published online: 18 January 2013

(C) Springer Science+Business Media New York 2013

Erratum to: J Abnorm Child Psychol

DOI 10.1007/s10802-012-9689-5

The original version of the article was published with error on spelling of the last author name. The correct spelling is Buitelaar, as shown above.

The online version of the original article can be found at http://dx.doi.org/ 10.1007/s10802-012-9689-5.

D. Bons · E. van den Broek · P. Herpers • N. Rommelse

Department of Psychiatry, Radboud University Nijmegen

Medical Centre,

Nijmegen, the Netherlands

F. Scheepers

Department of Child and Adolescent Psychiatry,

University Medical Centre Utrecht,

Utrecht, The Netherlands

J. K. Buitelaar $(\bowtie)$

Department of Cognitive Neuroscience,

Radboud University Nijmegen Medical Centre,

Nijmegen, the Netherlands

e-mail: j.buitelaar@psy.umcn.nl 